\section{Cost-cutting at CERN?}

SIR - As a British physicist who spends about one third of his time working at CERN, I am in a position to appreciate the difficult situation that has developed, and I should like to comment on your recent News story (Nature 379, 286; 1996).

First, CERN's new project, the Large Hadron Collider (LHC), was unanimously approved by the CERN member states in December 1994, on condition that the budget be frozen during 1995-97 and thereafter indexed 1 per cent per year assuming 2 per cent inflation. This approval was given only after CERN had found ways to make substantial cuts in running costs, and reluctantly proposed to end excellent programmes (for example LEAR, where antihydrogen was recently discovered) in order to make resources available for the LHC, which has an even higher priority.

Second, because CERN's budget is determined in Swiss francs, the dramatic fall in the value of the pound relative to the Swiss franc has caused a serious problem for the United Kingdom. However, the strength of the Swiss franc has not created a large windfall gain for CERN because 75 per cent of CERN's expenditure is in Swiss francs (on salaries, utilities and so on), while the remainder is mainly in currencies (especially the French franc and deutschmark) that have held up better than the pound relative to the Swiss franc.

Third, your reference to "a new salary award for CERN staff" gives a misleading impression and, incidentally, your statement that the United Kingdom voted against this year's budget is wrong: the United Kingdom voted against any indexation of salaries, not against the budget as such. In fact, CERN salaries were indexed 1.3 per cent inside a constant personnel budget, but 0.6 per cent was accounted for by increased contributions to the pension fund, leaving only a 0.7 per cent increase in take-home pay, compared with a 2.1 per cent rise in the Geneva cost-of-living index. It should also be noted that CERN salaries have been underindexed during each of the previous four years. CERN should of course be encouraged to continue the significant gains in "productivity" that have been achieved over the past few years.

None of this is to deny that the rise of the Swiss franc has created a very serious problem for the United Kingdom (and other CERN member states), exacerbated by the rise in UK gross domestic product, which has increased the UK share of the CERN budget. Unfortunately, the savings resulting from continued salary restraint and cost cutting will not be on the scale of the United Kingdom's problem, a 27 per cent increase in the cost in pounds over two years.

As chairman of the Advisory Committee of CERN Users, which represents the views of the 6,500 scientists who visit CERN to work on the experimental facilities, I am also aware of the complexity of the issues involved in deciding the appropriate salary levels, and that simply focusing upon one element of the salary settlement misrepresents the true situation.

\section{K. J. Peach}

Particle Physics Experiments Group,

Department of Physics and Astronomy,

University of Edinburgh,

Mayfield Road, Edinburgh EH9 3JZ, UK

\section{Warped view}

SIR - Cecil Fox's appeal (Nature 379, 292; 1996) that we should eschew all "fantasies" to abolish the public mistrust of science shows why the public are justified in their mistrust of at least some scientists.

John Maddox (Nature 378, 435-437; 1995), gave his first consideration to "exaggerated claims", but only to technology, not to ideology. Perhaps in his well-tempered valediction he overlooked the ability of some scientists to be blind to the boundary of their own expertise. To over-extend hardwrought knowledge into a universal and singular interpretation of truth and value begs to be described as puritanical.

First on Fox's hit-list of heresies is the "trivial" television series 'Star Trek' which, he asserts with certainty, "would fail to appeal to a public forearmed with a belief in the tidiness of thermodynamics". Just how does Fox categorize all those thermodynamically aware Trekkies, some of whom are, doubtless, among your readers ?

This school's current outline for its Year 7 (11-12 years old) course: 'Earth in Space' reads, under "know the extent of manned and unmanned space exploration":

"The film Apollo 13 makes a useful topical departure point at present. It is important to point out that the Apollo missions were remarkable because they were real; also point out that 'Star Trek' may have good story lines but is nonsense science."

Of course, the likes of Cecil Fox would not need to have the scientific aspects pointed out but they should recognize that a good comprehensive school like this one should be able to cater for those who show exceptional ability in only one part of the curriculum. He does not have to appreciate the quality of the treatment in 'Star Trek' of aspects of humanity and metaphor, but he should not assume that everyone else who is scientifically literate would find good creative writing and acting "trivial".

\section{Roger Macy}

Mascalls School,

Paddock Wood, Kent TN12 6LT, UK

\section{Organ transplants}

SIR - Two recent letters about xenotransplantation $^{1,2}$ require a response.

Mohacsi et al. ${ }^{1}$ stated that opposition to xenotransplantation has been expressed by the general community, and supported this statement by referring to a study carried out in the United States ${ }^{3}$. Far from demonstrating opposition to xenotransplantation, that survey indicates substantial support. Of 6,127 people surveyed, 85 per cent expressed general support for organ donation, and 79 per cent said they would accept an organ transplant if they needed one. The percentage approving the transplantation of animal organs when human organs were not available was 50 per cent, and 51 per cent would accept an organ transplant from an animal if a suitable human organ was not available. It should be remembered that these were the opinions of healthy men and women, who presumably doubted that they would ever need an organ transplant. My own opinion, based on 18 years in clinical heart transplantation, is that, if the survey had been carried out among patients awaiting a donor organ, the percentage who would have accepted a xenograft would have been very substantially higher.

Mohacsi et al. also refer to their own study carried out among acute care nurses in Australia, who were clearly opposed to the use of xenografts. It would be interesting to learn the views of these nurses on the use of pig heart valves and pig insulin in humans, two common forms of therapy that have been used for many years.

In the second letter, Robin Holliday ${ }^{2}$ drew attention to the fact that the life-span of domestic pigs may be relatively short, certainly not more than 20 years, and suggested that the success of xenotransplantation "might be completely foiled by the fairly rapid ageing of the transplanted heart". But one of the great advantages of xenografting would be that, if the organ fails (as unfortunately still occurs after allografting), a new organ is immediately and readily available. This remains the case with surgically implanted pig heart valves in humans which, despite their advantages, require replacement at intervals. Despite the inconvenience and small risk of undergoing sequential surgeries, these valves have saved many lives.

It is perhaps ironic that both of these rather 'negative' letters emanate from Australia, a country where much excellent research is being carried out in the field of xenotransplantation.

David K. C. Cooper

6700 NW Grand Boulevard,

Oklahoma City, Oklahoma 73116, USA

1. Mohacsi, P. J. et al. Nature 378, 434 (1995).

2. Holliday, R. Nature 378, 434 (1995).

3. The American Public's Attitudes Toward Organ Donation and Transplantation (Gallup/Partnership for Organ Donation, Boston, 1993). 